\title{
Chromatic Variation in Late Antique Rainbows
}

\author{
Bente Kiilerich
}

To ... add another bue onto the rainbow... is wasteful and ridiculous excess.

Shakespeare, King John, Act 4

\begin{abstract}
Depictions of rainbows in late antique and early Byzantine art follow the normal sequence of the spectral colours, only some bows exclude blue and violet. Another characteristic feature of the late antique rainbow is the inclusion of white and the non-spectral bue pink. In order to investigate chromatic characteristics, I use as case studies the comparatively few extant rainbow images of third- to sixth-century date from Thessaloniki, Constantinople, Rome and Ravenna. The rainbows, depicted in a floor mosaic, three illuminated manuscripts and three monumental wall mosaic decorations, are either part of narratives or rainbow-patterned borders used to frame other scenes. To throw light on the chromatic variations, ancient descriptions of rainbows are brought into the discussion and the representations are seen in relation to meteorological research.

I propose that the late antique rainbow images follow two visual traditions, both of which can be traced back to the Hellenistic period and both of which are grounded in scientific research. One is the sunrise/ sunset rainbow that ranges from red to green. I argue that the exclusion of blue/violet may be due to its being more difficult to see against the sky, the wavelength of violet being closest to the boundary beyond which coloured light tends to look black. The variant type, found especially in the church mosaics, covers the whole spectrum from red via green to violet as well as pink and white. I suggest that the nonspectral pink hues can be understood as the gradations of red that can sometimes be observed in the natural bow and that the white band provides highlight, which combined with a silver line indicates a strong luminance.
\end{abstract}

Keywords: rainbows, colour, late antiquity, mosaics, visual perception, meteorology, Aristotle, Ammianus Marcellinus

The dictionary defines a rainbow as 'an arch of colours formed in the sky in certain circumstances, and caused by the refraction and dispersion of the sun's light by rain or other water droplets in the atmosphere. The colours of the 
rainbow are generally said to be red, orange, yellow, green, blue, indigo and violet'. ${ }^{1}$ Although the bands of the rainbow are now referred to according to the Newtonian paradigm, these seven hues are not mandatory. At first Isaac Newton operated with eleven hues, then with five - red, yellow, green, blue and purple - but in order to have an analogous schema to the seven notes of the musical scale he ended up with the canonical seven, conceding, however, that of these orange and indigo were of less importance than the rest. ${ }^{2}$ The Newtonian ROYGBIV schema that has become prevalent in the Western world and is popular also for depictions of symbolic arcs in politics and mass media is only one of many ways to visualise the rainbow. ${ }^{3}$ Other cultures operate with still other chromatic divisions and designations. ${ }^{4}$ As for the Mediterranean area with which we are concerned, antique and Byzantine sources vary the number of hues from two or three to the poetic 'a thousand'. The inconsistency with regard to the number of colours and their designations can be explained by the fact that the rainbow does not consist of distinctive bands but of merging colours in a continuous spectrum.

The rainbow appears in the sky when the sun hits drops of rain. Each drop acts as a prism and refracts light. The primary rainbow is caused by light refracted into a raindrop, internally reflected once from its rear surface and refracted a second time towards the observer. ${ }^{6}$ From top to bottom the colours go from the longest wavelength, red, to the shortest, violet. In a double rainbow the colours are reversed: violet on the top, red on the bottom. The secondary bow is weaker because light is reflected twice within the raindrop. There may also appear a tertiary rainbow that is weaker still, but this is a very rare phenomenon. ${ }^{7}$ The supernumerary arc is a series of faint bands on the inner side of the bow. These usually alternate in pink and green. ${ }^{8}$ Alexander's dark band indicates the area between the primary and the secondary rainbow named after Alexander of Aphrodisias, AD 200, who first described the phenomenon. ${ }^{9}$

While a full arc spans the spectrum from bright red to dark violet, some bows show a more restricted range of colours. At sunset and sunrise when the sun is low to the horizon and the bow is closer to the earth, rainbows that contain neither blue, nor violet may appear. The colour and width of the bow depend on the size of the raindrops. An interesting phenomenon is the white rainbow: in foggy clouds with very tiny raindrops a white instead of a coloured

\footnotetext{
${ }^{1}$ New Oxford Dictionary of English 1998, 1531.

2 Newton 1704, I, II, 128; Kemp 1990, 285-287; Gage 1999, 133-143.

${ }^{3}$ For rainbows in politics and popular culture, see MacCannell 2018, 133-164.

${ }^{4}$ Dubois 2018.

${ }^{5}$ James 1991; James 1996, 92-109; Bradley 2009, 36-55.

${ }^{6}$ Lee \& Fraser 2001, 186.

7 Boyer 1958; Lee \& Fraser 2001, 290-292.

${ }^{8}$ Nussenzveig 1977, 116.

${ }^{9}$ Lee \& Fraser 2001, 110-111; Corradi 2016, 1.
} 
rainbow may appear; this is known as a cloud bow or fogbow. ${ }^{10}$ Indeed, rainbows differ so much in colour and shape that the French meteorologist Jean Richard proposed dividing them into twelve categories based on their visual characteristics. ${ }^{11}$

\section{Material and method}

In order to investigate chromatic characteristics and variations in depictions of rainbows in late antiquity, I use as case studies the few extant images from Thessaloniki, Rome, Constantinople and Ravenna of third- to sixth-century date. These images are respectively rainbows depicted in a floor mosaic, three illuminated manuscripts and three monumental wall mosaic decorations. The rainbows are either part of narratives or distinctive rainbow borders used to frame other scenes. ${ }^{12}$ I base my descriptions of colours in the mosaics on autopsy supplemented with digital and analogous photographs, while the descriptions of colours in the manuscripts are based on colour reproductions. In the study of the visual material must be taken into account that the rendering of a given bow depends on a number of factors such as the context, e.g. the floor of a private house versus the vaults of a church, and the medium - paint, stone or glass mosaic. Thus, a wider range of hues was available for wall mosaics in glass than for floor mosaics composed mainly of natural stone. Also, gradations of hues with gliding transitions were more easily rendered in paint than in the mosaic technique.

The illusive quality of rainbows and the transient nature of the inherent hues warn against distinguishing sharply between simple and complex, or 'symbolic' and 'naturalistic' rainbows in artistic depictions: all images are stylised representations of natural phenomena. One may, of course, expect a closer-to-nature appearance of rainbows in landscape paintings than in ornamental borders. A distinguishing feature in some ancient rainbow depictions is the omission of the blue-violet spectrum. I have therefore tentatively divided the material into bows missing the blue range and bows that include blue and/or violet.

\section{Rainbows missing blue and violet}

\section{The Chariot race mosaic from Thessaloniki}

A fragment of a pavement mosaic depicting the triumphal theme of a quadriga, two victory wreaths from the Pythian Games and the inscription arma (four-horse chariot) and synoris (two-horse chariot) decorated a large dining room floor in Thessaloniki. It dates from around AD 250-300 (Archaeological Museum, Thessaloniki) (Fig. 1). ${ }^{13}$ The representation is framed by a rainbow border, whose individual parts are set off clearly by means of

\footnotetext{
${ }_{10}$ Nussenzveig 1977, 122; Lee \& Fraser 2001, 244-247.

${ }^{11}$ Fessenden 2015.

12 Some cases of ornaments with rainbow hue patterning in floor mosaics have been left out.

13 Assimakopoulou-Atzaka 1998, 70, 341-342, pl. 55; Touratsoglou 1999, 128, fig. 162.
} 


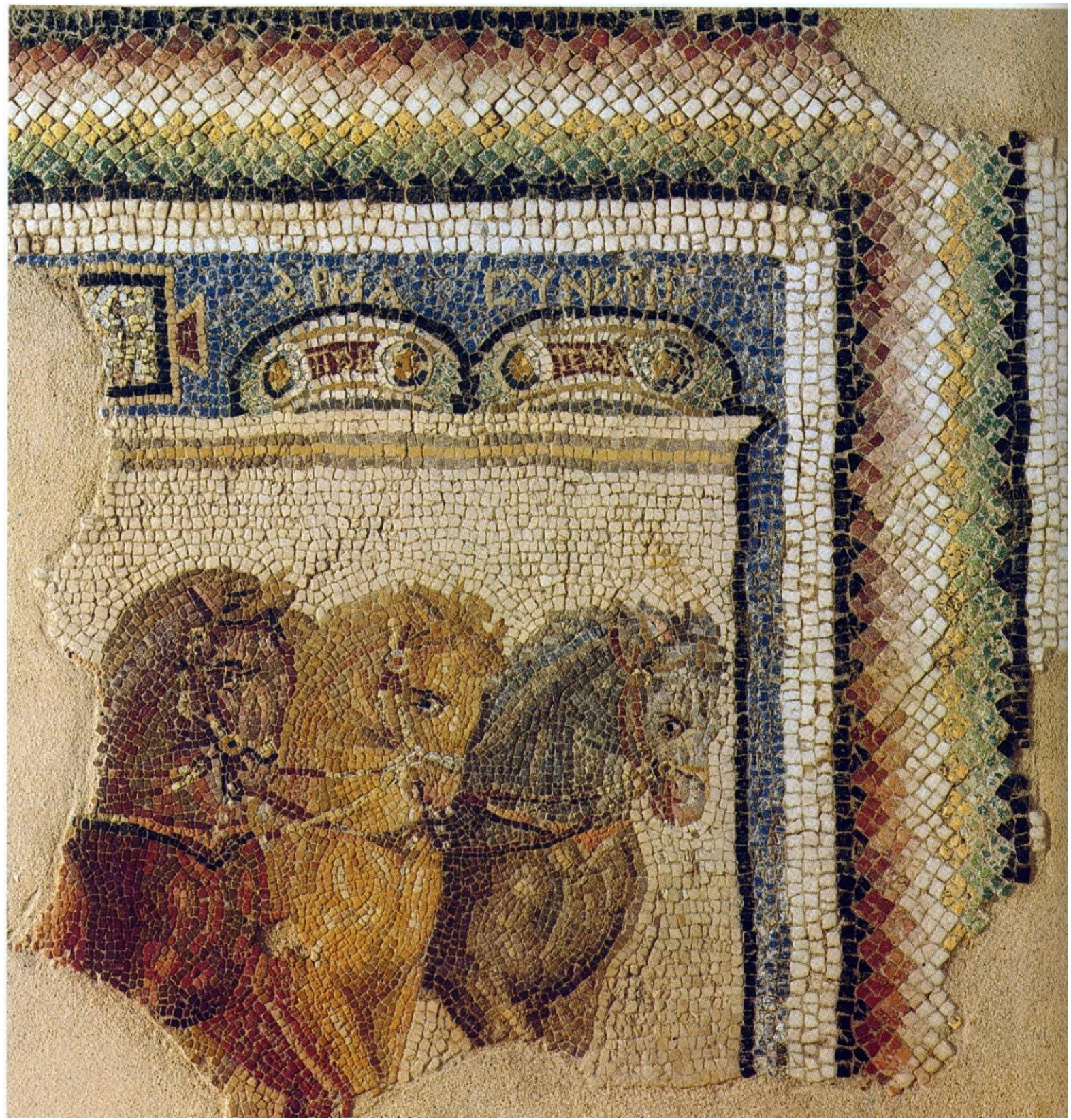

Fig. 1 Chariot race floor with rainbow border. Thessaloniki, Archaeological Museum. Photograph: Bente Kiilerich.

rows of differently coloured tesserae: from the horizontal upper edge the colours are red, orange-red, pale pink, white, yellow, light green, dark green. On the right it continues vertically in the reversed sequence. The rainbow design is edged on both sides by black triangles. Since blue tesserae have been employed as a background to the crowns and the inscription, the absence of blue in the rainbow is not due to restrictions of the medium. 


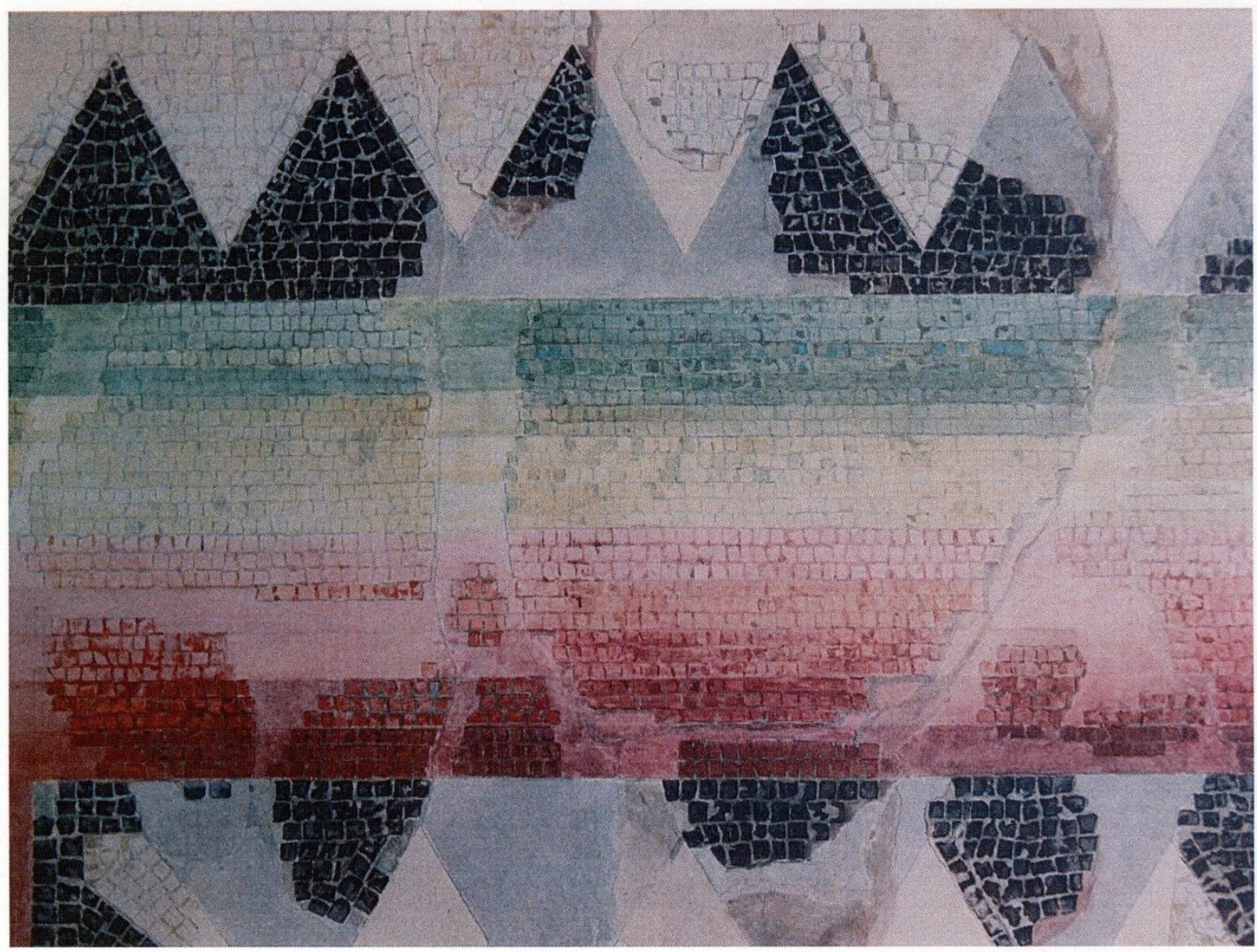

Fig. 2 Rainbow mosaic from Pergamon.

Photograph: (C) Kawerau \& Wiegand 1930, plate 8.

A related chromatic scheme is present already in the Rainbow mosaic from Pergamon, 197-159 BC. ${ }^{14}$ However, in contrast to the fewer, diamond-shaped rows at Thessaloniki, this mosaic has ten bands set in thirty even rows: dark red, medium red, orange-red, pink, pale pink, light yellow, yellow, yellowgreen, green and bluish green. As in the Thessaloniki floor, the design is edged with black triangles, here of conspicuously large size (Fig. 2). The mosaic is fragmentary and some of the colours that were actually painted onto white marble tesserae have faded; moreover, one has to rely on the approximate rendering of the hues of the published watercolour. These were presumably originally more saturated, the current pastel tone being somewhat misleading. Still, the mosaic provides important early evidence of the rainbow typology without blue and violet. It is particularly interesting to note that the floor from Thessaloniki presents almost the exact same colour sequence as the Rainbow mosaic. Thus, it may be suggested that the late antique rainbow reflects a visual tradition going back to the Hellenistic period.

\footnotetext{
${ }^{14}$ Kawerau \& Wiegand 1930, 54-56, pl. 8; Merker 1967; Pierce 1968.
} 


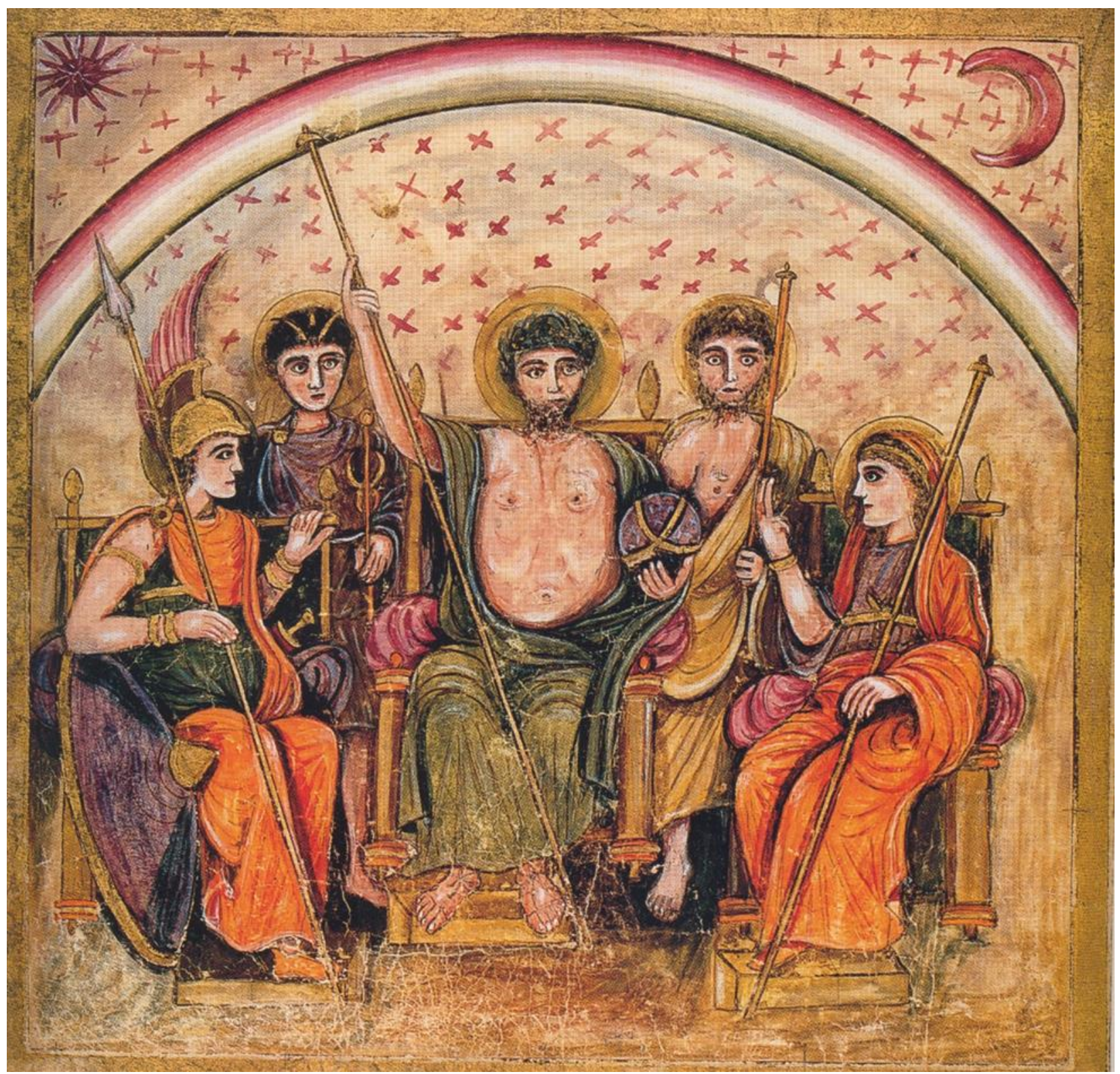

Fig. 3 Virgilius Romanus. Council of the Gods. Bibliotheca Vaticana. Photograph: C Wikimedia Commons.

\section{Vergilius Romanus}

The Vergilius Romanus manuscript of fifth-century date preserves nineteen fullpage illuminations. ${ }^{15}$ In two pictures showing the Council of the Gods (Bibliotheca Vaticana, fol. 234v, 235v), the rainbow arches over the enthroned gods. The bow is rendered in thin gradated bands of red, rose, white and greenish yellow (Fig. 3). ${ }^{16}$ The garments of the gods include both purple and blue; accordingly, as in the Thessaloniki floor, the exclusion of these colours from the arc is not due to a restricted palette. In another illumination, the

15 Rosenthal 1972.

16 Morelli 1996, 58. 


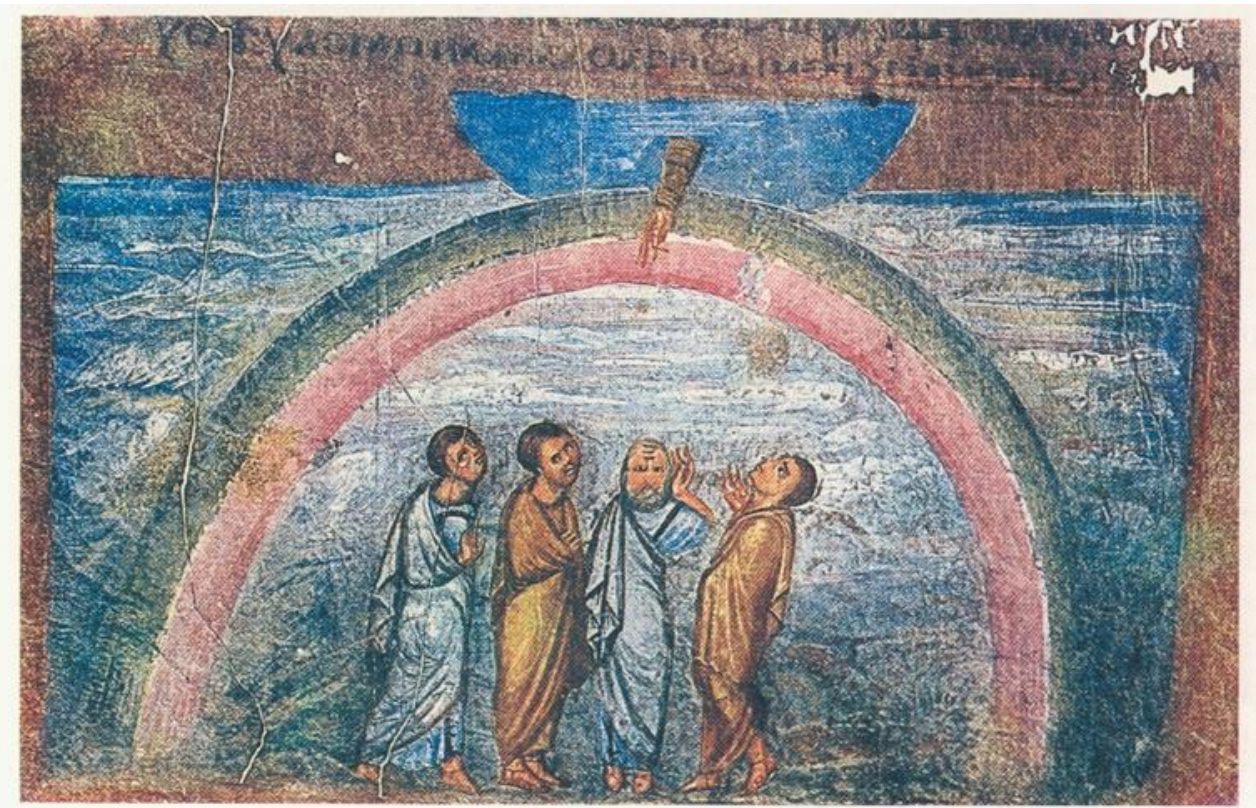

Fig. 4 Vienna Genesis. God's Covenant with Noah. Vienna. Österr. Nationalbibliothek. Photograph: (C) Wikimedia Commons.

personified rainbow Iris flows through the air dressed in green, yellow and red (fol. $74 \mathrm{v}$ ). The rainbow arching above her head like a billowing veil is depicted in the same colour scheme as in the Council of the Gods. Virgil refers to Iris 'dragging a thousand colours through the air' (Aen. 4. 700-702). ${ }^{17}$ By contrast, one might claim that the restricted colour gamut of the represented bow contradicts the poet's description of the 'mille colores'. At least, there is no direct correspondence between the visual and the verbal perceptions.

\section{Vienna Genesis}

In the illumination showing God's Covenant with Noah in the Vienna Genesis, similarly of fifth- or perhaps sixth-century date, a large bow arches over the figures (Vienna, Österr. Nat. Bibl., cod. theol. gr. 31, fol. 5). ${ }^{18}$ This is in accordance with the Bible's description of the 'bow in the cloud' as 'a token of a covenant' between God and the earth (Genesis 9.13). ${ }^{19}$ The chromatic emphasis is on the green outer and the red inner bands separated by a thin white line. The green band has been interpreted as the water of the deluge, the red as the fire of judgement day. ${ }^{20}$ However, in the late nineteenth century closer inspection by autopsy revealed subtly graded hues of dark green, light green, yellow/white, pink and red. ${ }^{21}$ In effect, the chromatic scheme is much the same as that of the rainbow images in the Vergilius Romanus manuscript, there being no difference between the pagan and the Christian bow (Fig. 4).

\footnotetext{
${ }_{17}$ Bradley 2009, 46-47.

${ }_{18}$ Kalpakidis 1997, 42-43, fig. 12.

${ }^{19}$ For this and subsequent references to the Bible, I have consulted the Authorised

Version (the King James Version).

${ }^{20}$ Gage 1993, 93, 98, fig. 64.

${ }^{21}$ Hartel \& Wickhoff 1895, 146-147.
} 


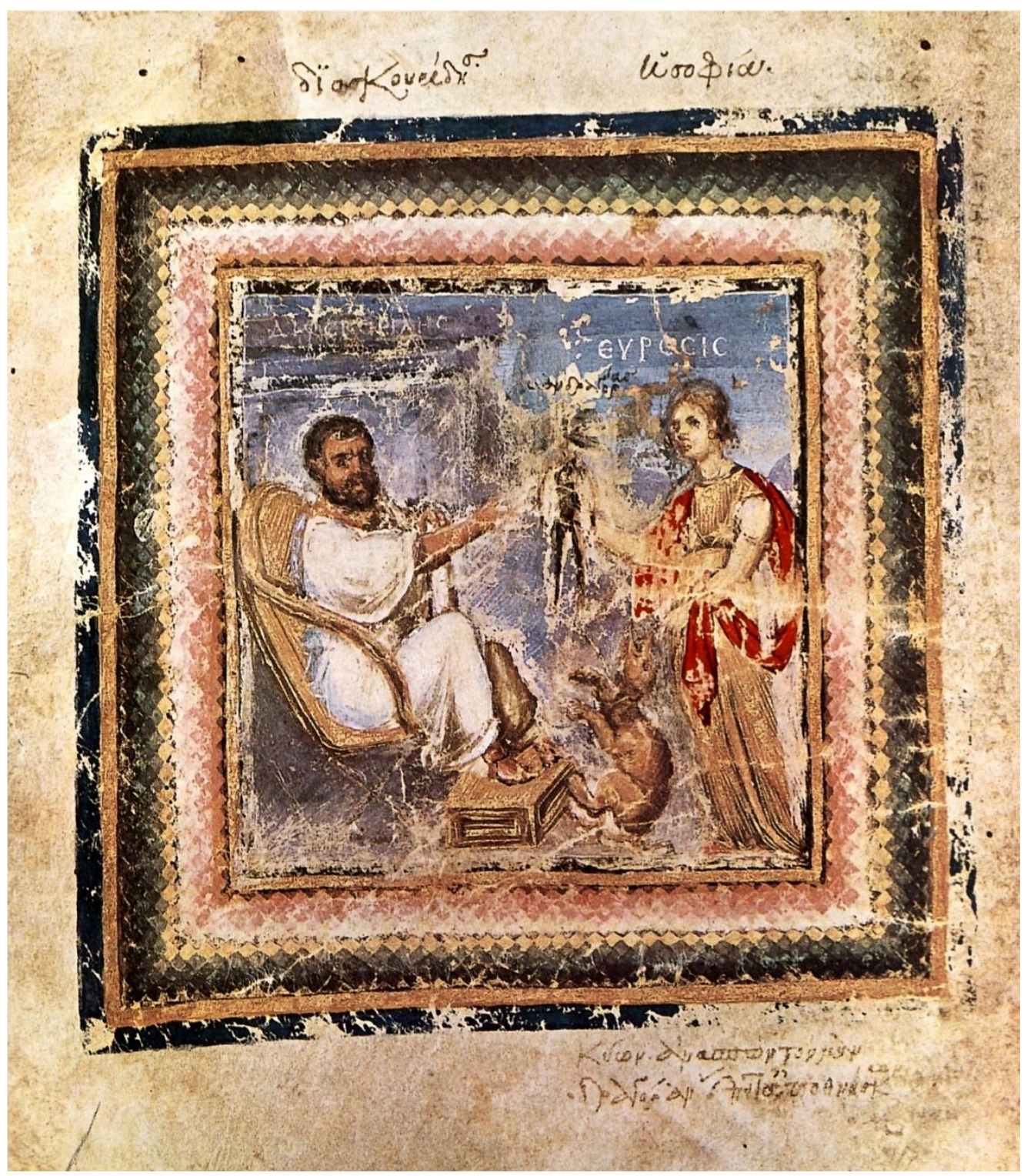

Fig. 5 Vienna Dioskurides. Rainbow border. Vienna. Österr. Nationalbibliothek. Photograph: C) Wikimedia Commons.

\section{Rainbows comprising blue and violet Vienna Dioskurides}

The Vienna Dioskurides is a large and lavishly decorated scientific codex, which was presented as a gift to the princess Anicia Juliana in Constantinople in AD 512 (Vienna, Österr. Nat. Bibl., cod. med. gr. 1). ${ }^{22}$ Six frontispieces with elaborate frames of various designs precede the more than 500 pages of plants. The image of Dioskurides receiving the mandrake root (fol. $4^{\mathrm{V}}$ ) is framed by coloured facets that range from a saturated hue at the outer edge via highlights in the middle to saturated hues along the inner edge. From the outermost to

22 Gerstinger 1979. 


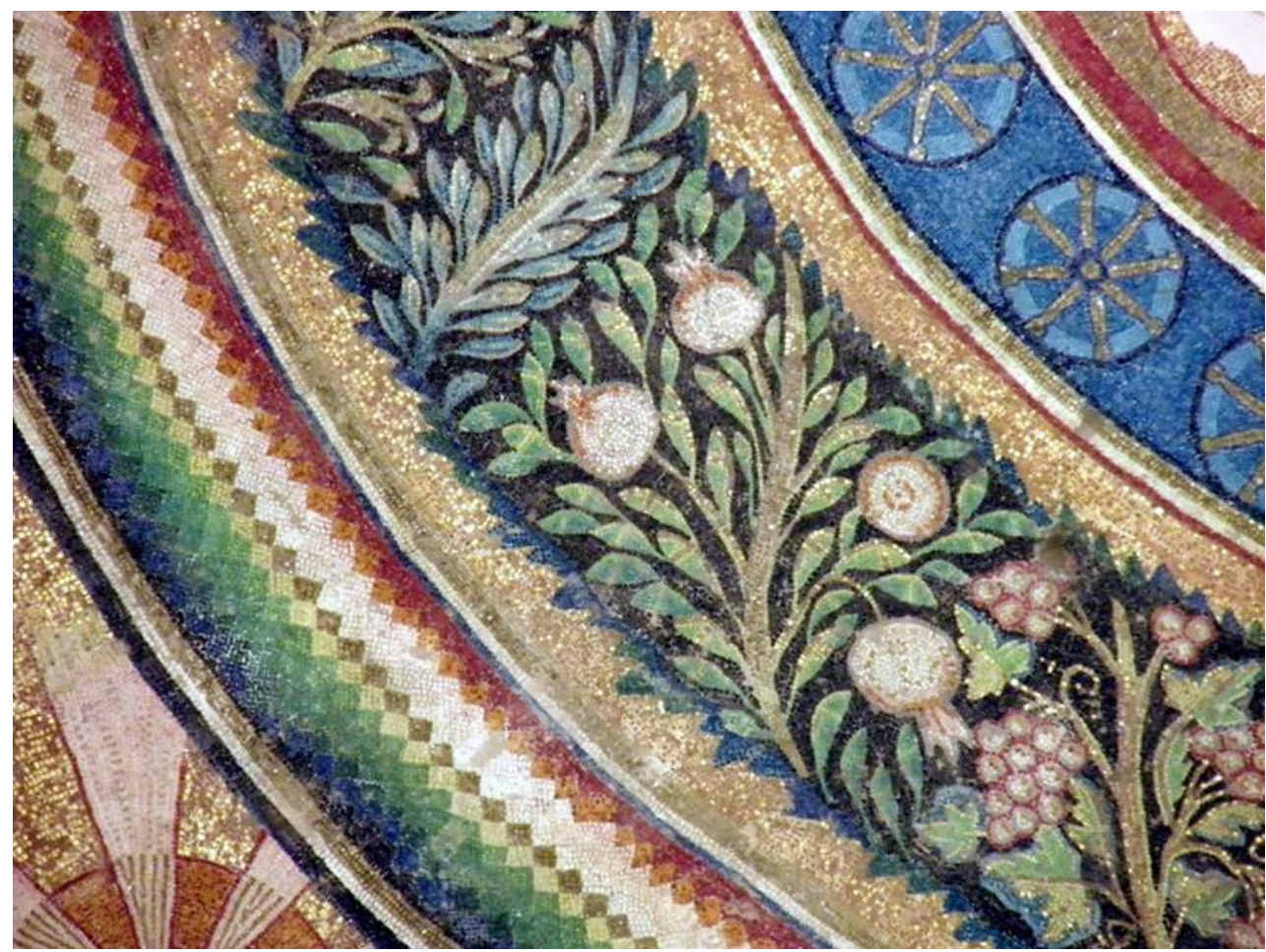

Fig. 6 Rotunda, Thessaloniki. Stars, floral wreath and rainbow border.

Photograph: Bente Kiilerich.

the innermost band this rainbow border shows: dark purplish, three greens, yellow, white, pale pink in two tones and red. ${ }^{23}$ (Fig. 5) With regard to the natural bow, the order is reversed. The reversal, seen also in other images, can be understood as the bow being conceived from the viewpoint of the persons depicted within the frame: if so, red actually becomes the topmost hue. The manner of painting with the colours arranged in indented diamond shapes reveals that the design imitates a floor- or wall mosaic, the border being very close to the one preserved in the Chariot race floor from Thessaloniki. The significant difference between the two is that another hue has been added to the rainbow: a dark colour, verging on violet (the precise colour is hard to define due to degrading of the pigments over the years).

\section{The Rotunda, Thessaloniki}

The inclusion of the short wavelength colour blue is seen especially in monumental Christian contexts where blue has become an integral part of the celestial arc. The most magnificent rainbow preserved from late antiquity is the one that encircles the mosaic medallion in the cupola of the Rotunda at Thessaloniki, dating from AD 380/390. The rainbow is part of an elaborate border in which the rainbow and a circle of stars frame a broader floral wreath (Fig. 6). ${ }^{24}$ These three concentric bands surround the divine apparition of the

\footnotetext{
23 Grabar 1966, 197, fig. 215.

24 Torp 2018, 358-378.
} 


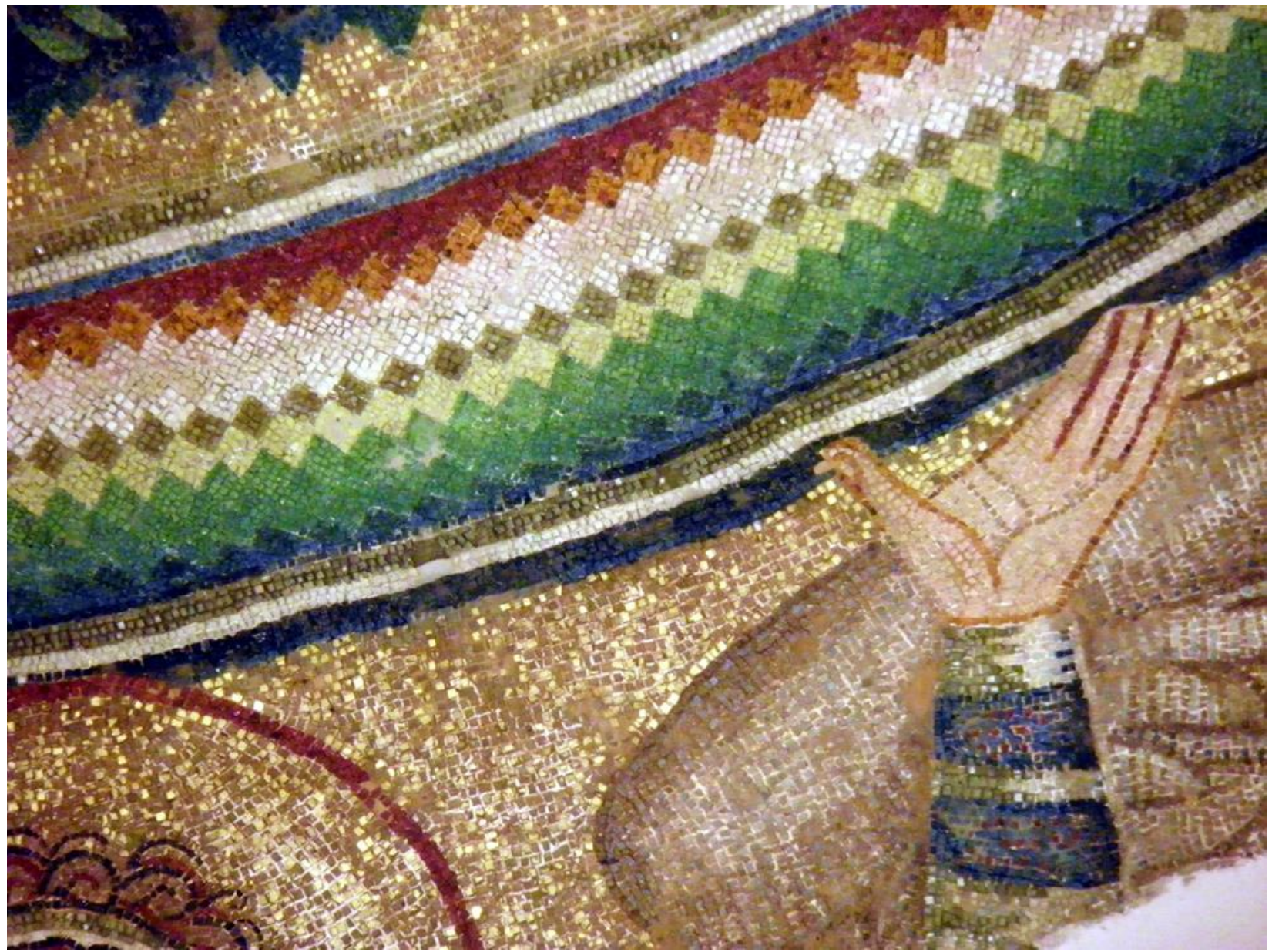

Fig. 7 Rotunda, Thessaloniki. Detail of rainbow border.

Photograph: Bente Kiilerich.

no-longer-extant Christ-Helios in the centre of the large medallion (see fig. 14). The silver stars suggest the light of the night, while the rainbow represents daylight. ${ }^{25}$ Light symbolism is further indicated by the light-emanating Phoenix and by rays of light that emanate from a (no-longer-extant) cross.

The iris makes up the $0.34 \mathrm{~m}$ broad exterior band of a circular triple border, whose diameter reaches an impressive $7.25 \mathrm{~m}$ (Fig. 7). ${ }^{26}$ Seen from the outermost band inward, the colours of the rainbow are: bluish violet, ultramarine, emerald green, bluish green, pale green, lemon yellow, silver, white, light pink, orange and red. Hjalmar Torp describes the bands of silver and marble as highlights in a basically Newtonian rainbow. ${ }^{27}$ The arc is set off on both sides with thin lines of black, ultramarine, white and now degraded silver. Although red is presented as the innermost band, the inverted order can

\footnotetext{
${ }^{25}$ Kiilerich \& Torp 2017, 50.

26 Torp 2018, 357.

27 Torp 2018, 358, 360, 365-366.
} 


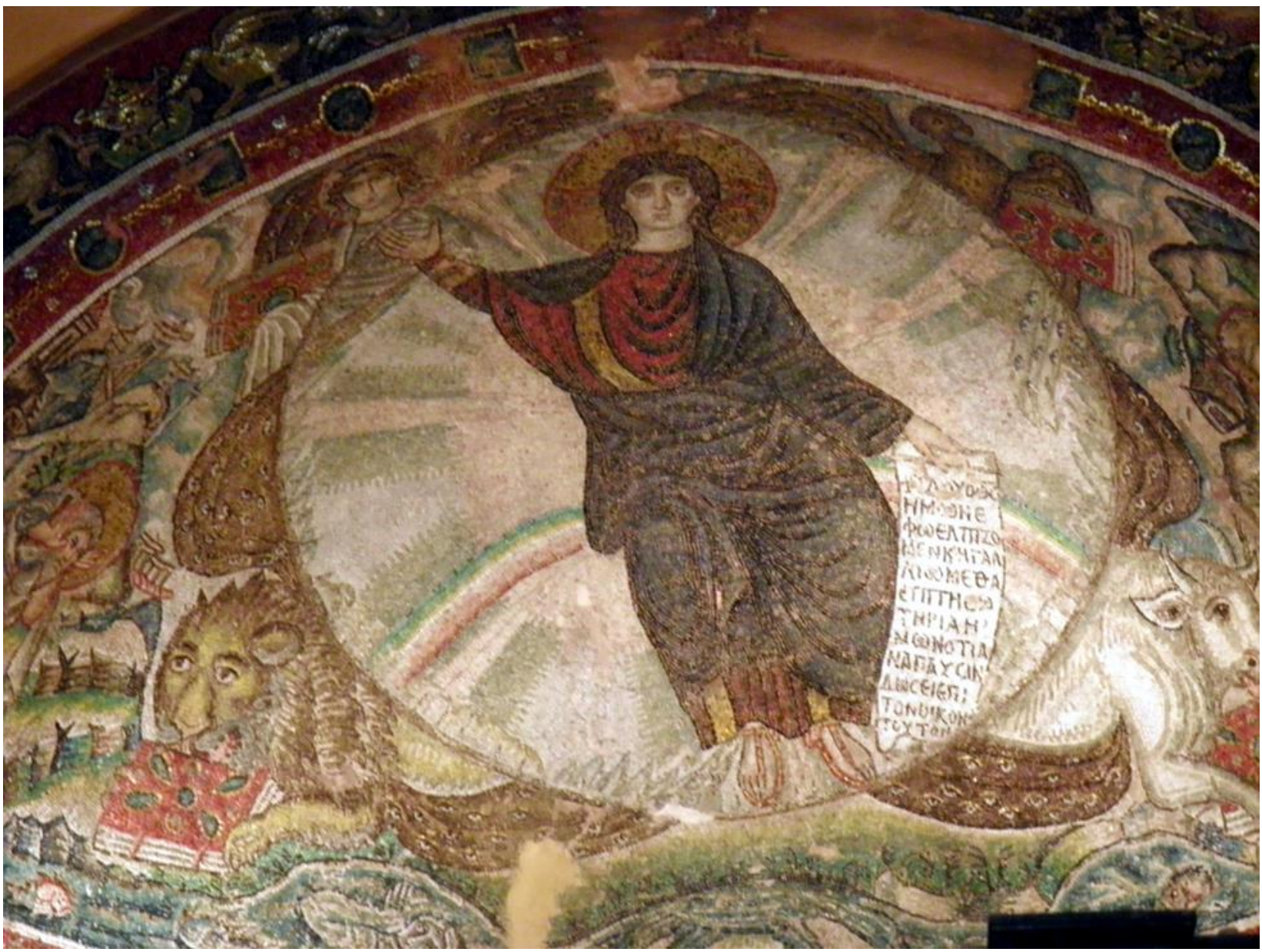

Fig. 8 Hosios David, Thessaloniki. Christ enthroned on rainbow border. Photograph: Bente Kiilerich.

be explained by the image being conceived from within, so that red is actually the top colour.

The violet hue is easily overlooked as it forms a very narrow band, that has become somewhat discoloured over time. Due to chemical reactions, a dark violet shade was difficult to fabricate in glass, as the colour tended to become maroon if iron was present but manganese wanting. ${ }^{28}$ The adjacent dark blue is more visible, but still plays a minor role in comparison with the preponderant green, which appears in three variant hues. The emphasis on green may reflect the description in the Bible of 'a rainbow [...] in sight like unto an emerald (smaragdos)' (Rev. 4.3). Liz James, however, believes that the smaragdos of the rainbow described in Revelation indicates brilliance rather than hue, which may also be the case, as luminance was generally more highly appreciated than hue in antiquity. ${ }^{29}$

\footnotetext{
${ }^{28}$ Fiori 1992, 51.

${ }^{29}$ James 1996, 96.
} 


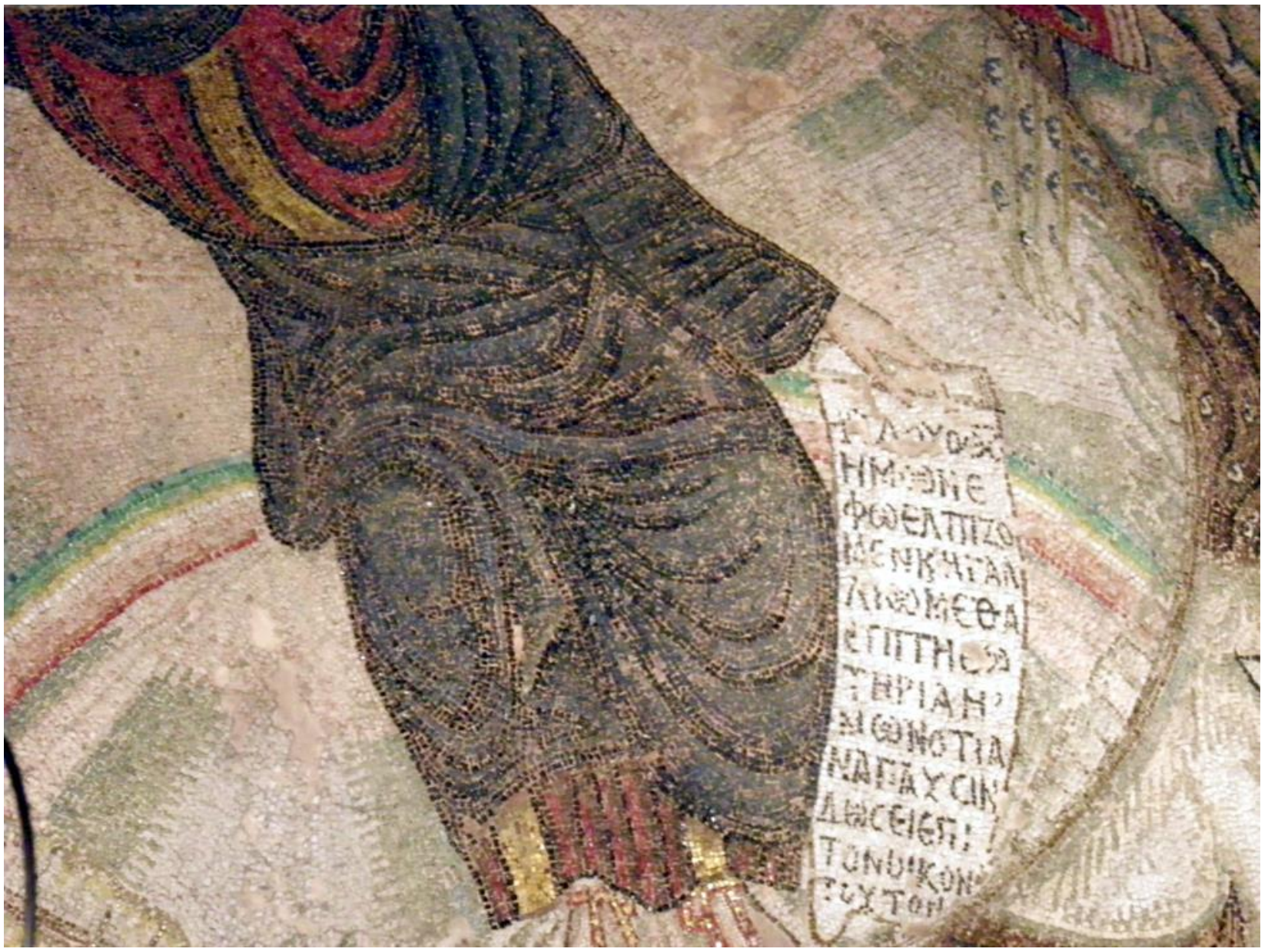

Fig. 9 Hosios David, Thessaloniki. Detail of rainbow throne.

Photograph: Bente Kiilerich

\section{Hosios David, Thessaloniki}

The mosaics of the small church of Hosios David, also known as Moni Latomou, in Thessaloniki post-date those of the Rotunda as certain ornamental motives are clearly inspired by the grandiose decorations of the monumental palatine church. Hosios David plausibly was decorated between 450 and 550. In the apse, Christ is revealed within a circle of light, seated on a rainbow of blue, green, yellow, white, rose, red and silver. ${ }^{30}$ Since red is placed innermost, the colours again are in reversed order. As in the Rotunda mosaic and the Dioskurides' manuscript, the arc should be seen not from our perspective but from Christ's angle of vision. The circle, or sphere, is entirely filled with various manifestations of light. It may contain both the supernumerary green and pink bows that sometimes appear near the rainbow and Alexander's dark band between the primary and the secondary bow. The glowing red behind Christ may represent the sun from which light is emanating in the form of blue, pink, rose and silver rays. The Hosios David

${ }^{30}$ Bakirtzis et al. 2012, 180-195; Torp 2017. 


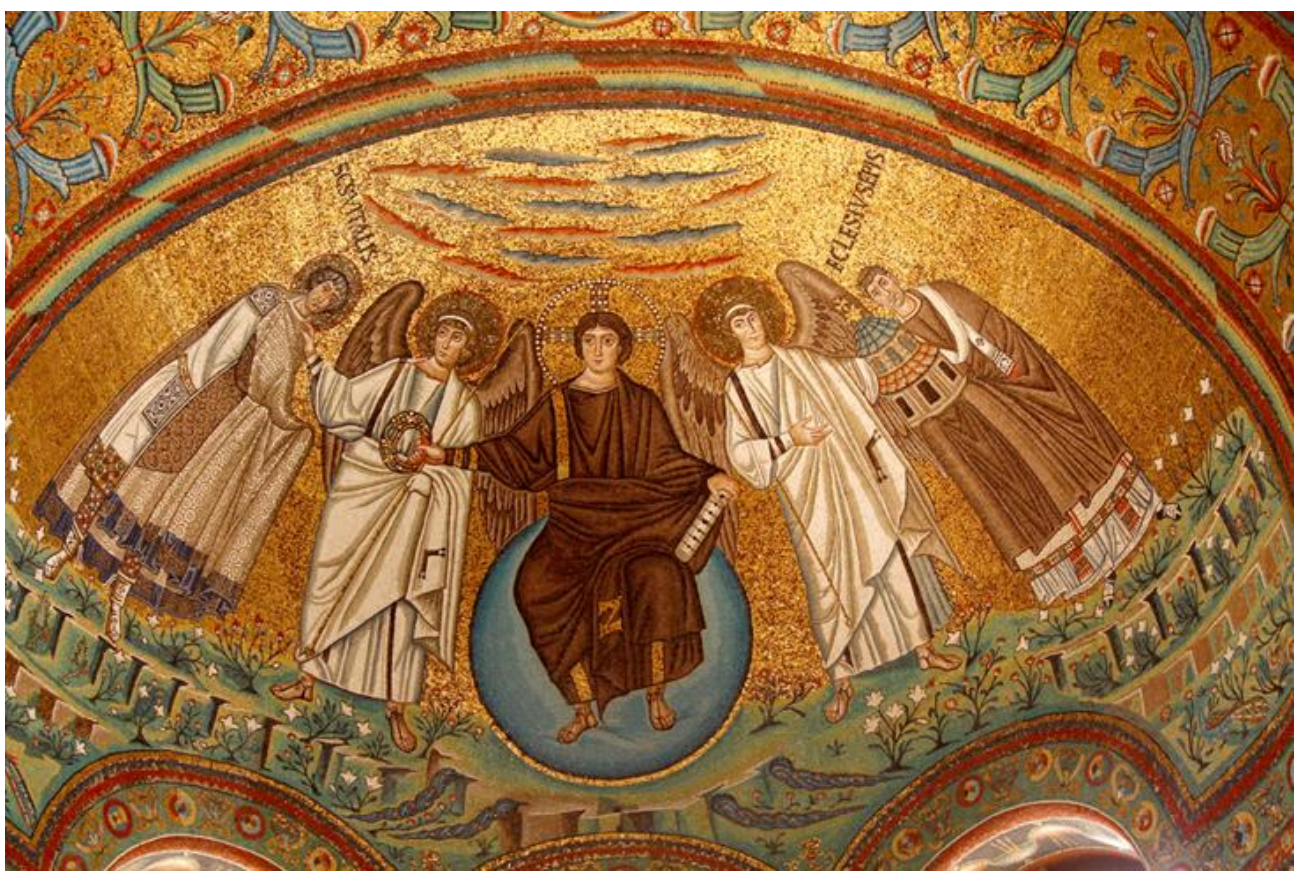

Fig. 10 San Vitale, Ravenna. Segmented rainbow. Photograph: Bente Kiilerich.

mosaic displays a sophisticated range of optical phenomena that probably are to be understood in connection with the complex overall message of the mosaic, which so far has not been fully revealed (Figs. 8-9). ${ }^{31}$

\section{Segmented rainbows in San Vitale, Ravenna}

In the mosaics of San Vitale, from around AD 540, the artists displayed chromatically varied bows relating to the specific themes they framed. ${ }^{32}$ It is worth noting that rainbows and rainbow patterns occur only in connection with images or symbols of Christ: 'As the appearance of the bow that is in the cloud in the day of rain so was the appearance of the brightness round about. This was the appearance of the likeness of the glory of the Lord' (Ezekiel 1.28). The rainbow framing the bust of Christ in the middle of the intrados is set in dark red, red, orange, pink, white, yellow, green and a thin band of blue. ${ }^{33}$ It is noticeable that blue, generally a highly appreciated colour in the mosaics is used quite sparingly. Instead of rendering the arc as a continuous band, one strategy was to dissect it. A rainbow border encircling a chrismon is divided into four segments: two show green as the outermost band, followed

\footnotetext{
31 See, e.g. Semoglou 2011-12.

32 McCannell 2018, 107, briefly mentions San Vitale without specifying the variation in the rainbows within the mosaic programme.

${ }^{33}$ Kiilerich 2019, 94, fig. 4.10.
} 


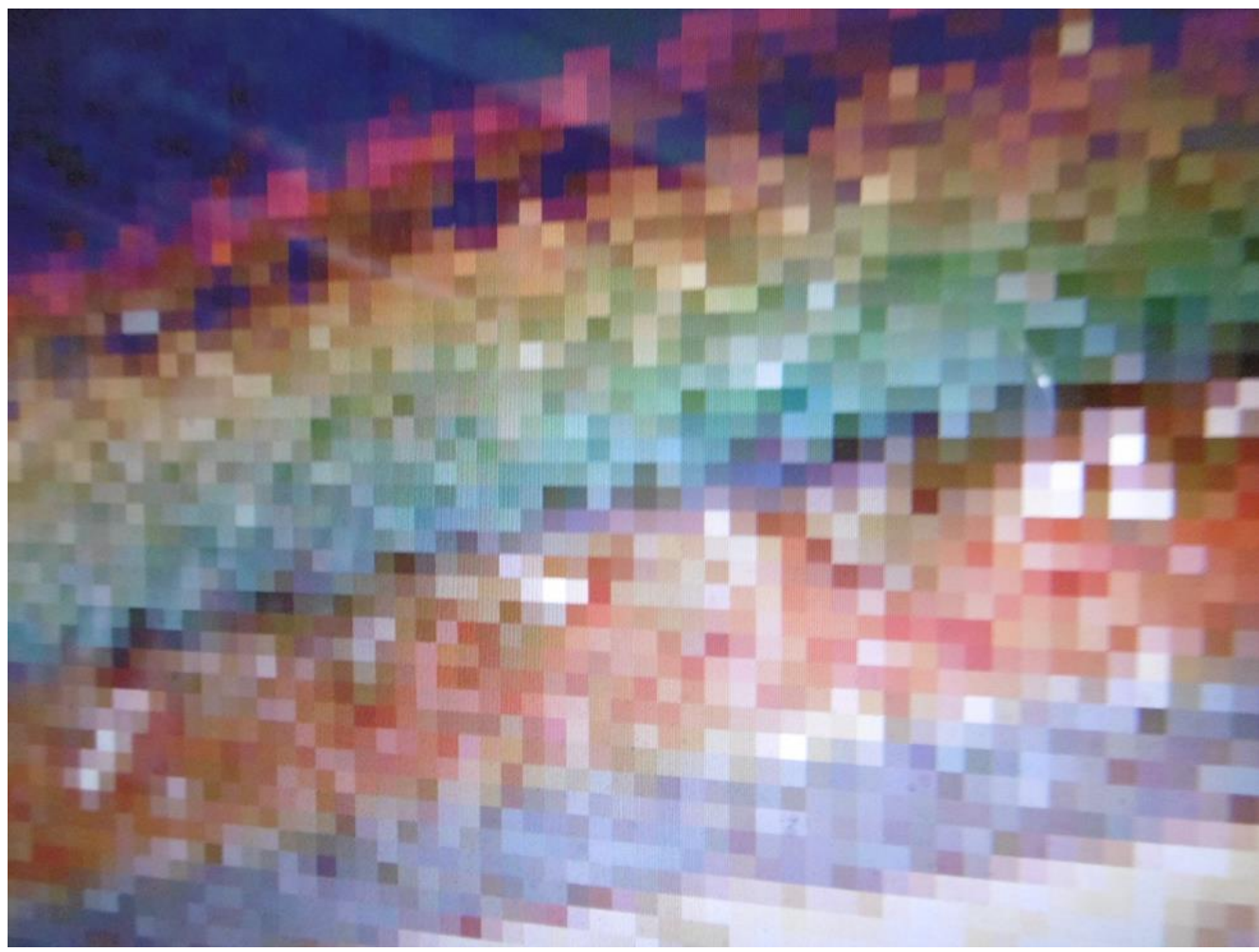

Fig. 11 San Vitale, Ravenna. Digital zoom (a.) of rainbow colours. Photograph: Bente Kiilerich.

by yellow, white, two reds and purple; the other two have a sequence of dark and light blue as the innermost bands, followed by white, red and purple.

A particularly important concept of a 'segmented rainbow', with the natural manifestation abstracted into an ornamental pattern, is encountered on the presbytery arch (Fig. 10). As a border along the arch of the presbytery, a continuous arc would have been an eloquent way of indicating the 'bow in the cloud' (Genesis 9.13) as represented in the Vienna Genesis. But the artists have cut the coloured band into pieces, dividing it into smaller segments turning in alternating directions. Thus, red is alternately on the outside and the inside of the different segments. ${ }^{34}$ The bow is rendered in purplish, red, pinkish-orange, silver, yellow, green, light blue; the chromatic scale is reversed in the adjacent section in a rhythm of A-B-A-B, somewhat as if a glimpse of a primary bow gives way to a glimpse of a secondary bow. As in the Rotunda mosaic at Thessaloniki, the bow is lined along the top and lower edge, here with degraded silver rays set against a red band and with a dark bluish violet band along the lower edge. Digital zooms of the pixilated image lay bare the intricate colour scale (Figs. 11-12).

${ }^{34}$ Kiilerich 2019, 83-84, figs. 4.7 - 4.8. 


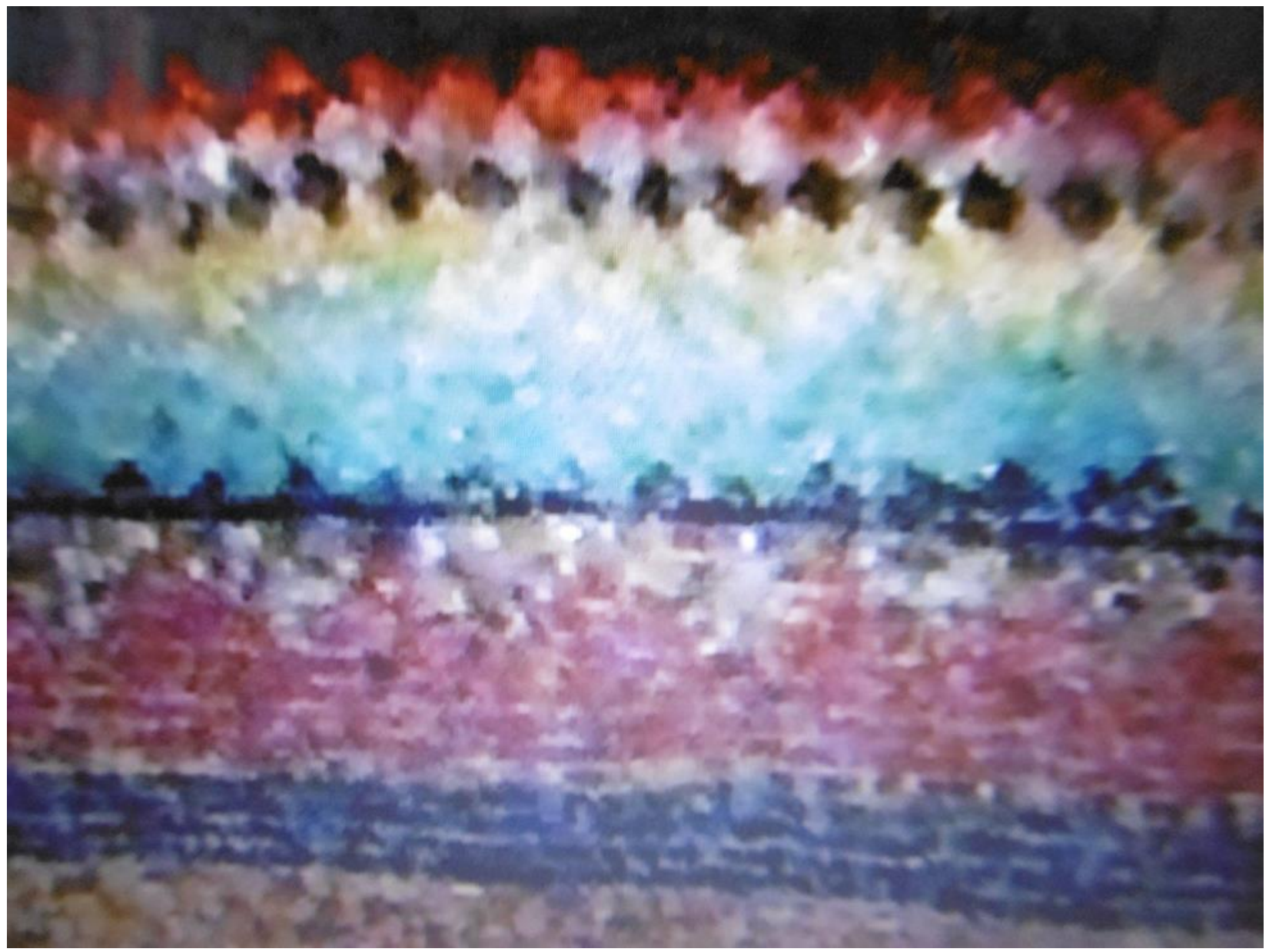

Fig. 12 San Vitale, Ravenna. Digital zoom (b.) of rainbow colours. Photograph: Bente Kiilerich.

\section{Perceptions of rainbow colours in works by ancient authors}

A number of ancient authors discuss or mention rainbows and their hues. It falls outside the scope of the present study to enter into a discussion of all texts relating to celestial arcs. ${ }^{35}$ In relation to the present enquiry, the most important source is Aristotle, whose theories of the rainbow have influenced debates down through the centuries. ${ }^{36}$ Around AD 200, Alexander of Aphrodisias (known from Alexander's dark band) commented on Aristotle's Meteorologica, and transmitted his ideas to the late antique world (Meteo. 139, 33-35). ${ }^{37}$ Another text that may have had an impact on ideas current in late antiquity is Ptolemy's Optics, written in Alexandria around AD 150-200. Unfortunately, this important work is not preserved in full and it can only be

\footnotetext{
35 Bradley 2009, 36-55 for an overview.

${ }^{36}$ Lee \& Fraser 2001, 105-111.

37 Ganson 2003.
} 
speculated whether Ptolemy could have addressed the optical phenomena of rainbows in one of the lost books. ${ }^{38}$

In the Meteorologica Aristotle discusses the colours and the characteristics of the rainbow over several pages $\left(3.371 b ; 372 a ; 375^{a} 4-11\right) .{ }^{39}$ He states that the three rainbow colours are foinikoun, prasinon and balourgon, roughly translated to red, green and bluish violet (372a 8). One controversial point is whether halourgon, sea-purple can be translated as blue, which is doubtful. ${ }^{40} \mathrm{At}$ least, since prasinon cannot translate to yellow, Aristotle did not name the three modern primaries red, yellow and blue. The philosopher Xenophanes, active around $530 \mathrm{BC}$, named the colours of the rainbow porfyreon, foinikeon and chloron (fragment 21b32). ${ }^{41}$ While porfyreos may be more purplish than halourgos ${ }^{42}$ and chloron a lighter and brighter green than prasinos, the general emphasis in Xenophanes is on red, green and violet as in Aristotle's rainbow. Incidentally, these hues correspond with colours of respectively long, medium and short wavelength with red peaking around 640, green at c. 540 and violet c. 440 nanometre. ${ }^{43}$

While claiming that there are only these three colours in the rainbow, Aristotle, nevertheless, admits that yellow (xanthon) sometimes appears between red and green: "The yellow colour (xanthon) that appears in the rainbow is due to the contrast of two others: for red (foinikoun) in contrast to green (prasinon) appears light/white (leukon)' (372a 10-11). Thus, while his theory is basically trichromatic, it does include a wider coloristic range. Aristotle continues '.. . the rainbow is purest when the cloud is blackest and in these circumstances the red appears more yellow. So the whole of the red appears light/white ...' (375a). 'The same thing happens, when the rainbow is fading and the red dissolving: for the cloud which is white, changes to yellow when brought next to green.' These observations are more or less in accordance with the visual images presented above.

Aristotle then refers to the phenomenon of the lunar rainbow (selenes iris). ${ }^{44}$ The moon rainbow looks entirely white (Met 375a 18). This is a rare phenomenon that according to the philosopher only occurs at full moon, and Aristotle has already informed that in a period of fifty years, he has only seen it twice (Met 372a, 22-29). As the name implies, the lunar bow is generated by moonlight and should not be confused with the cloud bow or fogbow that also has a predominantly white hue.

A late antique interest in rainbows and their various manifestations is encountered in the work of the historian Ammianus Marcellinus. Relating Emperor Constantius' campaign in the East in AD 360, Ammianus describes

\footnotetext{
38 Lejeune 1956; Smith 1996.

${ }^{39}$ Sayili 1939; Harry 1971. I have used the LCL edition, Aristotle 1962, transl. H.D.P. Lee.

${ }^{40}$ Harry 1971, not blue.

41 Bradley 2009, 38.

42 Kiilerich 2017, 49-52.

${ }^{43}$ Livingstone 2002, 14-23.

${ }^{44}$ Sayili 1939.
} 
the rainy season and the rainbows that were seen.$^{45}$ Having explained how the phenomenon of the arcus caelestis occurs (20.11.26), he goes on to name the colours of the bow: the first is luteus, saffron yellow; next comes flavescens or fulva, golden yellow ('orange'?); punicea, red, is third; purpurea, purple, is number four; and the last is caerulo concreta et viridi, blue growing into green. Ammianus presents the hues in an unexpected order by placing the yellow tones before the red. He explains that the first part appears more diluted because of the surrounding air; the golden yellow is more vivid, while red is exposed to the brightness of the sun and absorbs its brilliance most purely. The purple has a flame-like appearance; the more this colour spreads it passes over into blue and green (20.11.28). In sum, the whole spectrum is included in this exposition, although with purple/violet next to red rather than at the opposite end of the spectrum. Ammianus' multi-coloured rainbow is quite close to those encountered in the early church mosaics.

Ammianus subsequently proposes another explanation of the rainbow as the result of a thick cloud filled with the rays of the sun: 'It takes the colours nearest to white (albo colores) from the sun higher up, but the greenish (subvirides) shades from resemblance to the cloud just above it' (20.11.30). Ammianus' rainbow glowing in the colours nearest to white combined with the green ones below is reminiscent of the way the artists of the Vergilius Romanus and the Vienna Genesis rendered the phenomenon.

\section{Discussion: rainbows with and without blue and violet}

The rainbows of the Vergilius Romanus, the Vienna Genesis and the Chariot race mosaic in the main line follow the formula established already in Hellenistic mosaics as witnessed in the Pergamon floor. Gloria Merker associated the Rainbow mosaic from Pergamon with Aristotelean colour theory. ${ }^{46}$ But she failed to account for its missing halourgon, which suggests that it may derive from a different tradition. Blue and violet pigments are expensive and theoretically one might imagine these shades to have been left out because they were in short supply. Still, since the 'blueless' late antique works all include blue and violet in other parts of their vividly coloured images, the exclusion of these hues in the rendering of rainbows and rainbow patterned borders and frames was not caused by material or economic restrictions.

It is sometimes claimed that language shapes how we see colour and that the reason for artists depicting only a limited number of rainbow hues, mainly red, white and green, was caused by a lack of words: they could only show the hues for which they had specific linguistic terms. Thus, contrary to the archaeological evidence cited above, Eckstut and Eckstut present the common view that 'as late as the twelfth century, the arc is portrayed only in red and green, with a band of white running through its center. It was not until the Renaissance that rainbows took on additional hues', and further, '... awareness

\footnotetext{
45 Bradley 2009, 44-45. For Ammianus' text, I have used the LCL, transl. J.C. Rolfe.

46 Merker 1967.
} 


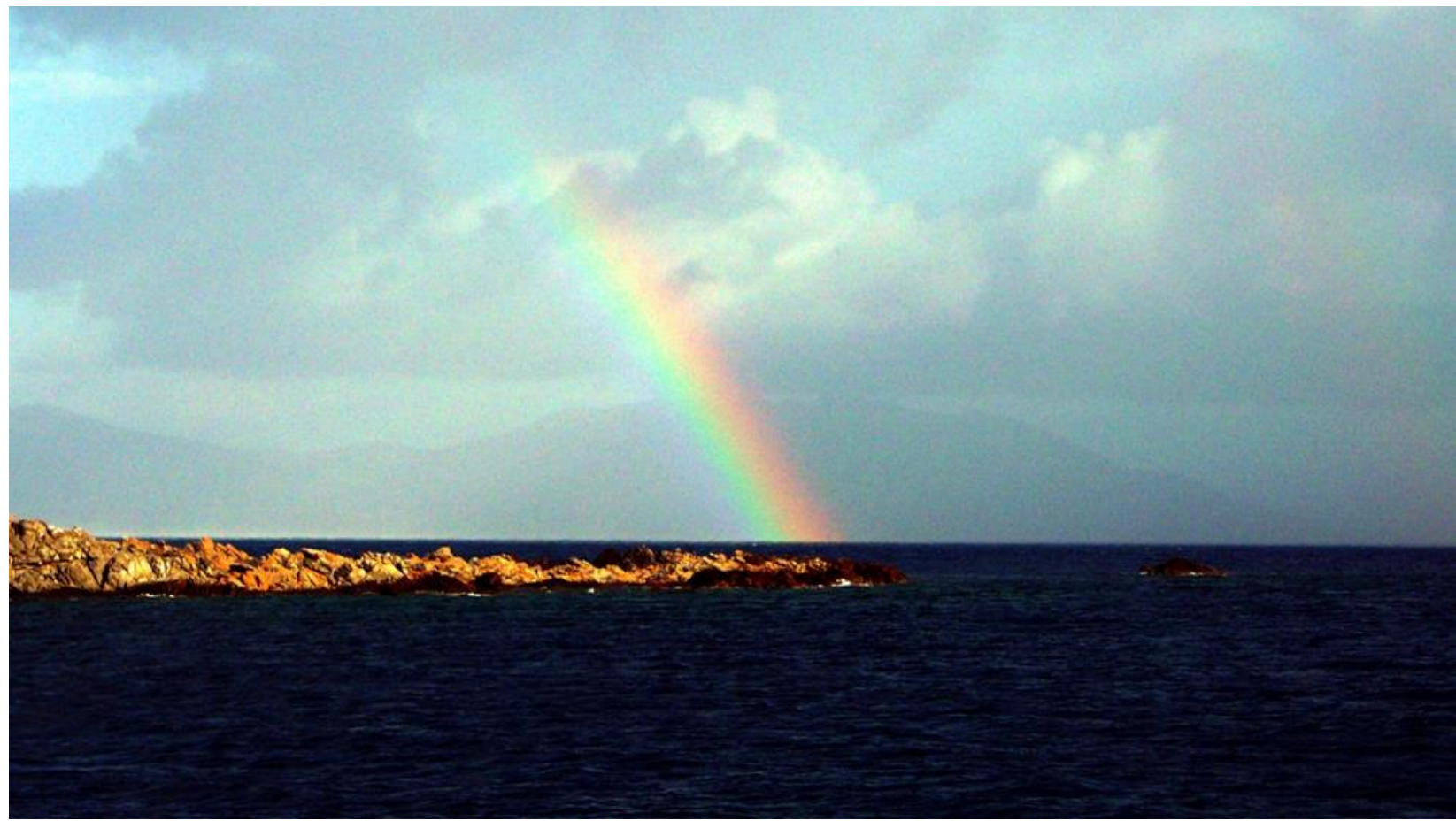

Fig. 13 Rainbow over Mykonos, late morning October 2010. Photograph: Bente Kiilerich.

of a color was developed partially based on what language was available. ${ }^{, 47}$ But terms for the blue to violet range do of course exist in both Greek and Latin (kyanos, halourgos, porphyreos, caeruleus, purpureus, etc.). Thus linguistic limitations should not have prevented artists from drawing bands of blue and violet. ${ }^{48}$

Why then did some artists render 'blueless' rainbows? Meteorologists have demonstrated that for drops with a radius larger than $0.3 \mathrm{~mm}$, blue disappears from the rainbow. ${ }^{49}$ Since one does not always see all the spectral colours in a given bow, and since occasional rainfalls with large drops are more usual than drizzle in the Mediterranean area, it is perhaps unsurprising if rainbows with strong blue and violet bands were seldom observed and recorded. A rainbow seen by the present author at Mykonos, in October 2010, shows predominantly pink, yellow and green, the other hues being only faintly discernible (Fig. 13). In this - as in many other manifestations of celestial arcs - the colours merge into one another so that the dominant red hue gradates into pinkish and yellowish tones, whereas the blue is more difficult to make out against the sky. ${ }^{50}$

\footnotetext{
${ }^{47}$ Eckstut \& Eckstut 2013, 208.

48 See in general, André 1949; Dürbeck 1977. Old Norse has some fourteen terms for blue, Wolf 2007, 53-54. Blue or its cognate is also part of the description of rainbows in various non-Western cultures, see e.g. Dubois 2018.

${ }^{49}$ Lee \& Fraser 2001, 260.

${ }^{50}$ Nussenzveig 1977, 117 shows a photograph of a rainbow in British Columbia with a strong pinkish component.
} 


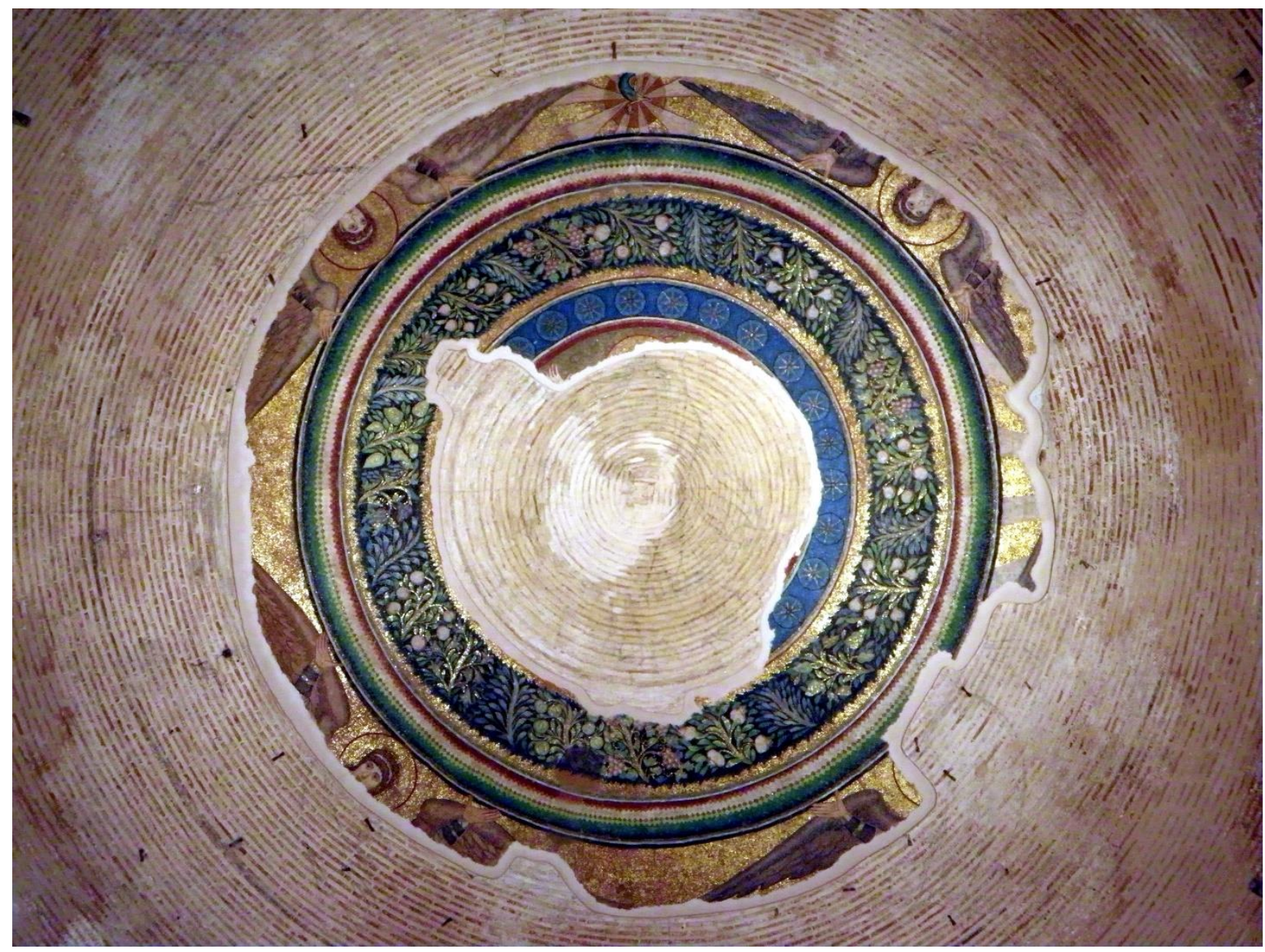

Fig. 14 Rotunda, Thessaloniki. Cupola medallion with full rainbow circle. Photograph: Bente Kiilerich.

In contrast to the red-green dominance of the arcs in the illuminated manuscripts and the floor mosaic, the most complex chromatic range is encountered in the wall-mosaics of the Rotunda and San Vitale. It is reasonable to assume that the monumentality of the churches led to a more elaborate rendering of rainbows than the one encountered in pavements. Since the seasonal wreath in the Rotunda contains plants, flowers and fruit of all the seasons - a comprehensive expression of eternity - the rainbow may be said to contain elements of all rainbow manifestations including the spectral hues, the red sunrise and the white lunar rainbow. The Rotunda iris - like the smaller equivalents in San Vitale - is designed as a circular frame and actually displays an entire rainbow circle, as if seen from a very high point such as the top of a mountain (Fig. 14). The rainbow is 'an image of the sun, albeit a wildly 
distorted one'. ${ }^{51}$ The rainbow framing the apparition of Christ-Helios in the cupola can therefore be understood as his reflection.

In both multi-coloured and 'blueless' rainbows, the acromatic white is a common component. ${ }^{52}$ As noted above, when raindrops are very tiny the bow may appear white instead of in colour. ${ }^{53}$ The silver line next to white in the Rotunda and San Vitale rainbows and the silver rays in the latter may have been added in order to display the iridescent nature of the porphyreos iris, stressing that the colours of the rainbow glitter. In combination with lenkon, which means not only white, but also light and bright, the impact of the highlighted area of the arc increases. ${ }^{54}$

Most late antique rainbow mosaics are set off against or lined with black. The black colour might suggest Alexander's dark band between the primary and the secondary bow. However, it is probably most likely to indicate the dark sky against which the rainbow appears. The human eye is unable to detect light out of certain boundaries, and colours then fade to black. ${ }^{55}$

\section{Conclusion}

Despite a certain stylisation, late antique rainbow depictions are in accordance with meteorological observations. They follow two variant, but related typologies. One is the sunrise/sunset arc that ranges from red, via yellow to green, often depicted as consisting of gradations of red, white and green. This limited chromatic range is seen in the floor mosaic from Thessaloniki, AD 250/300 and in the illuminations of the Vergilius Romanus and the Vienna Genesis of the fifth/sixth century. It being depicted in a Pergamene floor of second century $\mathrm{BC}$ date suggests that the 'blueless' rainbow derives from a Hellenistic tradition. It is meteorologically correct inasmuch as when raindrops are large, blue disappears from the bow. The second type of bow covers (almost) the whole spectrum from the long wavelength red to the short wavelength blue, verging on violet. The complex chromatic scale of the multicoloured rainbow is especially characteristic of Christian mosaics in monumental contexts, e.g. the Rotunda and Hosios David in Thessaloniki and San Vitale at Ravenna. Although there is no definite proof, Aristotle's description of the dominant rainbow colours as red, green and violet with some yellow in between hints that this typology is similarly of Hellenistic or earlier origin. As for the sparse use of violet in the Rotunda and Hosios David, it should be noted that even more than blue, the shortest wavelength violet often vanishes to the sight, being less visible against the sky. The exclusion of violet in some bows can therefore be explained by its being more difficult to see against the sky, its wavelength being closest to the boundary beyond which

\footnotetext{
${ }^{51}$ Lee \& Fraser 2001, 121.

52 Many later painters, for instance Turner and Constable, have painted rainbows with much white, see Gage 1993, 103, fig. 72.

${ }^{53}$ Lee \& Fraser 2001, 244-247.

${ }^{54}$ For leukon and other white/light colour terms, see Reiter 1962, 20-77.

55 Corradi 2016, 7: below $400 \mathrm{~nm}$ and over $750 \mathrm{~nm}$ colours look black to the human eye.
} 
coloured light tends to look black. In ancient art, white and pink are ubiquitous rainbow hues. White may be understood as a way to give visual form to the multitude of imperceptible hues within the celestial arc. Given that it is often combined with silver, white also represents highlight. The pinkish bands are gradations of red, the dominant rainbow colour. Disregarding the fact that pink is a non-spectral colour it is in fact often possible to perceive both bright and pale pink hues in the natural bow.

The circumstance that we have been conditioned to perceive rainbows in the light of the seven Newtonian spectral colours may be an impediment to seeing the colour gamut noted by ancient viewers. Given that rainbows appear infrequently in the Mediterranean area, the artists who endeavoured to catch celestial arcs are unlikely to have taken their clues directly from observations of nature. They must have followed visual traditions and verbal prescriptions. However, these prescriptions did, of course, have their ultimate origin in natural observations like the ones recorded by Aristotle and handed down to later generations. Since the colours of the rainbow are evanescent, the hues gliding almost imperceptibly into one another, and since rainbows change their appearance from one moment to the next and two people never see the exact same colours, rainbows allow for a multitude of visual perceptions - as evidenced by the late antique images of celestial arcs.

Professor Bente Kiilerich

University of Bergen

Dept. of linguistic, literary and aesthetic studies

N-5020 Bergen

Bente.Kiilerich@,uib.no 


\section{References}

André, J. 1949: Étude sur le termes de couleur dans la langue latine. Paris: Klincksieck.

Assimakopoulou-Atzaka, P. 1998: Syntagma ton palaiochristianikon psefidoton dapedon tis Ellados. III.1: Ta psefidota dapeda tis Thessalonikis. Thessaloniki: Kentro Byzantinon Ereunon.

Bakirtzis, Ch., Kourkoutidou-Nikolaïdou, E. \& Mavropoulou-Tsioumi, Ch. 2012: Mosaics of Thessaloniki $4^{\text {th }}-14^{\text {th }}$ Century. Athens: Kapon Editions.

Boyer, C. B. 1958: 'The Tertiary Rainbow: an Historical Account', Isis 49: $141-$ 154.

Bradley, M. 2009: Colour and Meaning in Ancient Rome. Cambridge: Cambridge University Press.

Corradi, M. 2016: 'A Short History of the Rainbow', in Lettera matematica international edition, 1-9, DOI 10.1007/s40329-016-0127-3. Available at link.springer.com. (accessed 12 November 2019).

Dubois, A. 2018: 'Couleurs de l'arc-en-ciel et anthropologie', in A. Dubois, J.P. Eczet, A. Grand-Clément \& C. Ribeyrol (eds), Arcs-en-ciel \& couleurs, 25-43. Paris: CNRS.

Dürbeck, H. 1977: Zur Charakteristik der griechischen Farbenbezeichnungen. Bonn: Diss.

Eckstut, J. \& Eckstut, A. 2013: The Secret Language of Color. New York: Black Dog.

Fessenden, M. 2015: 'Not All Rainbows have Every Color', (22 December 2015), https://www.smithsonianmag.com/smart-news/not-all-rainbows-haveevery-color-180 (accessed 3 November 2019).

Fiori, C. 1992: 'Studio della composizione e del degradi dei materiali musivi dell'arco presbiteriale di S. Vitale a Ravenna', in A. M. Iannucci (ed.), Mosaici a S. Vitale e altri restauri, 45-53. Ravenna: Longo editore.

Gage, J. 1993: Colour and Culture. Practice and Meaning from Antiquity to Abstraction. London: Thames \& Hudson. 
Gage, J. 1999: Colour and Meaning: Art, Science and Symbolism. Berkeley: University of California Press.

Ganson, T. 2003: 'Alexander of Aphrodisias on the Role of Color Appearances', Ancient Philosopby 23: 383-393.

Gerstinger, H. 1979: Dioscurides, Codex Vindobonensis Med. Gr. 1 der Österreichischen Nationalbibliothek (facsimile). Graz: Akademische Druck- und Verlagsanstalt.

Grabar, A. 1966: L'age d'or de Justinien. Paris: Gallimard.

Harry, B. E. 1971: 'A Defence of Aristotle, Meteorologia 3, 375ªff.', The Classical Quarterly 21: 397-401.

James, L. 1991: 'Colour and the Byzantine Rainbow', Byzantine and Modern Greek Studies 15: 66-95.

James, L. 1996: Light and Colour in Byzantine Art. Oxford: Clarendon Press.

Kalpakidis, I. E. 1997: Ta chromata sti 'Genesi tis Biennis'. Kavala: Kalpakidis.

Kawerau, G. \& Weigand, Th. 1930: Die Paläste der Hochburg (Altertümer von Pergamon V, 1). Berlin: W. de Gruyter.

Kemp, M. 1990: The Science of Art. Optical Themes in Western Art from Brunelleschi to Seurat. New Haven \& London: Yale University Press.

Kiilerich, B. 2017: 'Colour, Light and Luminosity in the Rotunda Mosaics', in A. Eastmond \& M. Hatzaki (eds), The Mosaics of Thessaloniki Revisited, 48-61. Athens: Kapon Editions.

Kiilerich, B. 2019: 'Abstraction in Late Antique Art', in C. Olovsdotter (ed.), Envisioning Worlds in Late Antique and Early Byzantine Art, 77-94. Berlin: de Gruyter.

Kiilerich, B. \& Torp, H. 2017: The Rotunda in Thessaloniki and its Mosaics. Athens: Kapon Editions.

Lee, R. L. jr. \& Fraser, A. 2001: The Rainbow Bridge. Rainbows in Myth, Art, and Science. University Park: The Pennsylvania State University Press.

Lejeune, A. 1956: L'optique de Claude Ptolémée, dans la version latine d'après l'arabe de l'émir Eugène de Sicile (Recueil de travaux d'histoire et de philologie $4^{\mathrm{e}}$ série, fasc. 8). Louvain: Publications Universitaires. 
Livingstone, M. 2002: Vision and Art. The Biology of Seeing. New York: Abrams.

MacCannell, D. 2018: Rainbows. Nature and Culture. London: Reaktion Books.

Merker, G. S. 1967: 'The Rainbow Mosaic at Pergamon and Aristotelean Color Theory', AJA 71: 81-82.

Morelli, G. (ed.) 1996: Illustration. Ten Centuries of Illustration from the Most Precious Mediaeval and Renaissance Codices in Existence, Biblioteca Apostolica Vaticana. Rome: Fratelli Palombi editori.

Newton; I. 1704: Opticks, or, a Treatise of the Reflexions, Refraxions, Inflexions and Colour of Light. London: Sam. Smith \& Benj. Walford.

Nussenzveig, H. M. 1977: 'The Theory of the Rainbow', Scientific American 236, no. 4: 116-128.

Paul, S. 2017: Chromaphilia. The Story of Colour in Art. London: Phaidon.

Pierce, R. H. 1967: 'The Rainbow Mosaic at Pergamon and Aristotelean Color Theory', AJA 72: 75.

Reiter, G. 1962: Die griechischen Bezeichnungen der Farben Weiss, Grau und Braun. Eine Bedeutungsuntersuchung. Innsbruck: Universitätsverlag Wagner.

Rosenthal, E. 1972: The Illuminations of the Vergilius Romanus (Cod.Vat.Lat. 3867). Zurich: Urs-Graf-Verlag.

Sayily, A. M. 1939: 'The Aristotelean Explanation of the Rainbow', Isis 30: 6583.

Semoglou, A. 2011-12: 'La mosaïque de "Hosios David" à Thessalonique. Une interpretation néotestamentaire", Cahiers archéologiques 54: 5-16.

Smith, A. Mark. 1996: Ptolemy's Theory of Visual Perception: An English Translation of the Optics with Introduction and Commentary (TAPS 86, pt. 2). Philadelphia: American Philosophical Society.

Torp, H. 2017: 'Thessaloniki. Church of Hosios David', in P. C. Finney (ed.), The Eerdmans Encyclopedia of Early Christian Art and Archaeology, vol. II, 598-599. Grand Rapids: William B. Eerdmans Publishing Company.

Torp, H. 2018: La rotonde palatine à Thessalonique: architecture et mosaïques, vols. I-II. Athens: Kapon Editions. 
Touratsoglou, I. 1999: La Macedoine. Histoire. Monuments. Musées. Athens: Ekdotiki Athenon.

Wolf, K. 2007: 'The Colors of the Rainbow in Snorri's Edda', Maal og Minne 1: 51-62. 